\title{
Sonochemical Synthesis of Cobalt Ferrite Nanoparticles
}

\author{
Partha P. Goswami, ${ }^{1}$ Hanif A. Choudhury, ${ }^{2}$ \\ Sankar Chakma, ${ }^{1}$ and Vijayanand S. Moholkar ${ }^{1,2}$ \\ ${ }^{1}$ Department of Chemical Engineering, Indian Institute of Technology Guwahati, Guwahati, Assam 781 039, India \\ ${ }^{2}$ Center for Energy, Indian Institute of Technology Guwahati, Guwahati, Assam 781 039, India
}

Correspondence should be addressed to Vijayanand S. Moholkar; vmoholkar@iitg.ernet.in

Received 8 August 2013; Revised 28 September 2013; Accepted 4 October 2013

Academic Editor: Jose C. Merchuk

Copyright (C) 2013 Partha P. Goswami et al. This is an open access article distributed under the Creative Commons Attribution License, which permits unrestricted use, distribution, and reproduction in any medium, provided the original work is properly cited.

Cobalt ferrite being a hard magnetic material with high coercivity and moderate magnetization has found wide-spread applications. In this paper, we have reported the sonochemical synthesis of cobalt ferrite nanoparticles using metal acetate precursors. The ferrite synthesis occurs in three steps (hydrolysis of acetates, oxidation of hydroxides, and in situ microcalcination of metal oxides) that are facilitated by physical and chemical effects of cavitation bubbles. The physical and magnetic properties of the ferrite nano-particles thus synthesized have been found to be comparable with those reported in the literature using other synthesis techniques.

\section{Introduction}

The spinel ferrite nanoparticles have exceptional electronic and magnetic properties, which are quite different from the bulk materials [1]. As a result, the magnetic ferrite nanoparticles have found wide applications in information storage systems, ferrofluids, and medical applications like magnetic drug delivery and hyperthermia for cancer treatment [2]. Among metal ferrites, zinc, nickel, and cobalt ferrites have been mostly applied. Cobalt ferrite $\left(\mathrm{CoFe}_{2} \mathrm{O}_{4}\right)$ is a hard magnetic material that is known to have high coercivity and moderate magnetization [3]. On nanoscale, the cobalt ferrite achieves properties of high saturation magnetization, high coercivity, strong anisotropy, high mechanical hardness, and high chemical stability [4]. Conventional techniques for synthesis of metal nanoparticles (including cobalt ferrite particles) are sol-gel method $[5,6]$, microemulsions $[7,8]$, reverse micelles [9], autocombustion, [10] and coprecipitation [11]. A relatively new technique for synthesis of ferrite nanoparticles is the sonochemical route [12-16], in which the reaction mixture is exposed to ultrasound irradiation. Spectacular physical and chemical effects induced by ultrasound bring about the synthesis of metal ferrites from the metal salt precursors, usually acetates. The hydrolysis of acetates, followed by oxidation of the hydroxides to oxides and the reaction between oxides to yield ferrites is brought about by ultrasound and its secondary effect, cavitation. Cavitation is essentially nucleation, growth and transient implosive collapse of gas bubbles driven by ultrasound wave [17]. This technique has been well demonstrated for zinc ferrites. In our previous papers $[15,16]$, we have tried to illuminate the links between physics of ultrasound and cavitation and the chemistry of zinc ferrite nanoparticles. It was revealed in these studies that chemical species produced during transient cavitation induce the hydrolysis and oxidation of hydroxides, while shock waves generated by transient cavitation bring about the calcination of metal oxides to form ferrites [18].

In this study, we have extended the same theme for synthesis of cobalt ferrite. We would like to specifically mention that sonochemical preparation of cobalt ferrite nanoparticles has already been reported by Shafi et al. [19]. However, in their study the precursors were the metal carbonyls, which were sonochemically decomposed in decalin solvent to yield amorphous oxides that further reacted to form ferrites (with external calcination at 450 and $700^{\circ} \mathrm{C}$ ) that also had amorphous character. The major problem with this route is the use of toxic and hazardous metal carbonyl precursors. Our approach is more environmentally friendly in that the 


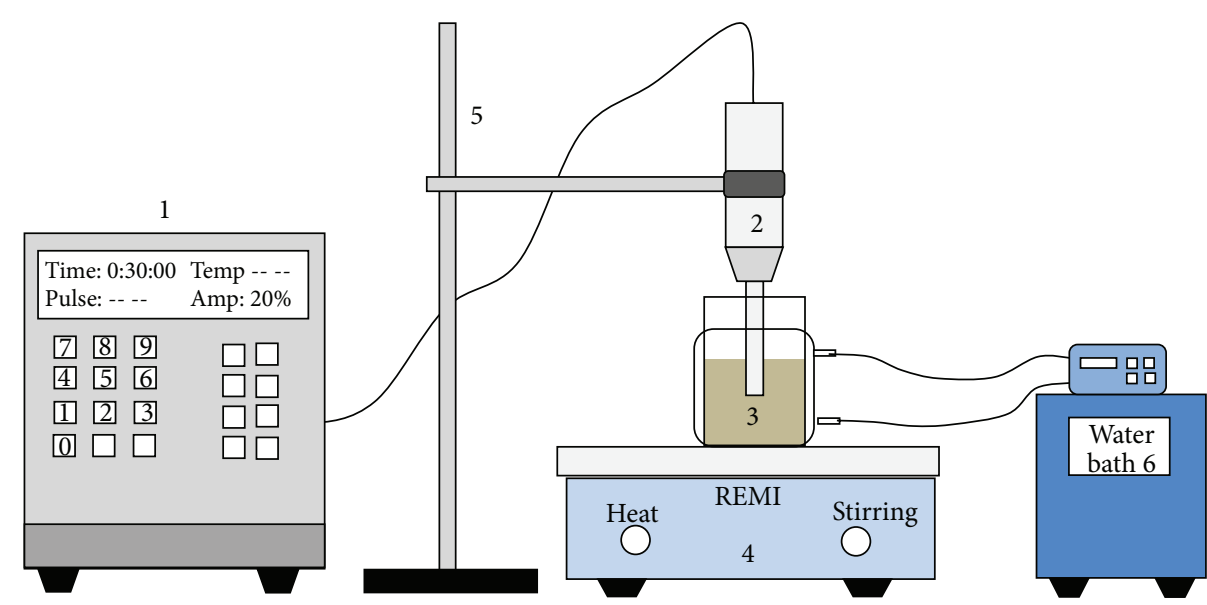

FIGURE 1: Schematic diagram of experimental setup for sonochemical synthesis of manganese ferrite. (1) Sonic processor, (2) transducer, (3) reaction mixture, (4) magnetic stirrer with hot plate, (5) stand, and (6) water cooler.

precursors used by us are cobalt acetate and iron (II) acetate. The characterization of the particles has been made using XRD, FE-SEM, and VSM.

\section{Materials and Methods}

The experimental parameters as well as analysis in this paper are based on results of these previous papers, as well as some preliminary studies (not reported in this paper). The main hypothesis on which this paper is based is that physical and chemical effects of cavitation bubbles induce the chemistry of ferrite synthesis. The metal acetates first undergo hydrolysis, thermal decomposition, and oxidation of hydroxides thus formed gives metal oxides, which are insoluble and precipitate in reaction mixture. The metal oxide particles get drifted in the shock waves generated by cavitation bubbles and collide at high velocities. The energy generated from these collisions can induce reaction leading to formation of ferrites. All of these steps have been well proven by previous researchers. Sonochemical hydrolysis and thermal decomposition are well-known reactions (for example Kotronarou et al. [20]). High energy collisions between particles induced by shock waves have also been proven by Doktycz and Suslick in a landmark paper [18].

2.1. Materials. The following chemicals have been used for the synthesis: cobalt acetate tetrahydrate (AR Grade, Merck), iron (II) acetate (AR Grade, Alfa Aesar), and $\mathrm{NaOH}$ pellets (Merck). All chemicals were used as received without any further purification. All the reaction mixtures were prepared using deionized water from Milli-Q Synthesis unit (Model: Elix 3, Millipore ${ }^{\circledR}$, USA).

2.2. Experimental Setup. A schematic diagram of the experimental setup is shown in Figure 1. All experiments were carried out with $20 \mathrm{~mL}$ of Millipore water in a borosilicate glass beaker. A desired amount of cobalt acetate was taken with iron (II) acetate and was placed on a hot plate (Remi Equipments Ltd., Model: 1-MLH). The ultrasound was applied for $30 \mathrm{~min}$ using a high grade titanium alloy ultrasonic probe (dia $13 \mathrm{~mm}$ ) with a frequency of $20 \mathrm{kHz}$ (Model: VCX-500, $20 \mathrm{kHz}, 500 \mathrm{~W}$ ). The probe was operated at $20 \%$ amplitude with theoretical power dissipation of $100 \mathrm{~W}$ $(500 \mathrm{~W} \times 0.20=100 \mathrm{~W})$. The microprocessor based control unit of the processor had facilities of automatic frequency tuning and amplitude compensation, which delivers constant power to the reaction mixture during the sonication period, irrespective of the changes occurring in the reaction medium. The acoustic pressure amplitude generated by the ultrasound probe was measured using calorimetric method as mentioned by Sivasankar et al. [21]. For $20 \%$ of the theoretical maximum power, the pressure amplitude produced by the probe was determined as 1.5 bar.

2.3. Synthesis Procedure. An amount of $0.708 \mathrm{~g}$ of cobalt acetate $(0.2 \mathrm{M})$ was taken in a $20 \mathrm{~mL}$ of Millipore water with $1.39 \mathrm{~g}$ of iron (II) acetate $(0.4 \mathrm{M})$ making the molar ratio of cobalt acetate to iron (II) acetate $1: 2$. The solution was subjected to sonication for $30 \mathrm{~min}$ in a pulse mode $(20 \mathrm{~s}$ on $-5 \mathrm{~s}$ off) with actual total sonication time of $24 \mathrm{~min}$. The temperature of the solution was maintained at $70^{\circ} \mathrm{C}\left( \pm 4^{\circ} \mathrm{C}\right)$ during the experiment. The initial $\mathrm{pH}$ of the reaction mixture in all protocols was 4.5. The $\mathrm{pH}$ of the solution was adjusted to the desire value by dropwise addition of either $0.1 \mathrm{~N} \mathrm{NaOH}$ or $0.1 \mathrm{~N} \mathrm{HCl}$. No external $\mathrm{H}_{2} \mathrm{O}_{2}$ was added to the reaction mixture during the synthesis of cobalt ferrite nanoparticles, as required for the oxidation of ferrous hydroxide. The exact chemistry of the cobalt ferrite synthesis is given by following chemical reactions:

$$
\begin{gathered}
\mathrm{Fe}\left(\mathrm{CH}_{3} \mathrm{COO}\right)_{2}+2 \mathrm{H}_{2} \mathrm{O} \longrightarrow \mathrm{Fe}(\mathrm{OH})_{2}+2 \mathrm{CH}_{3} \mathrm{COOH} \\
3 \mathrm{Fe}(\mathrm{OH})_{2}+\mathrm{H}_{2} \mathrm{O}_{2} \longrightarrow \mathrm{Fe}_{3} \mathrm{O}_{4}+4 \mathrm{H}_{2} \mathrm{O} \\
\mathrm{Co}\left(\mathrm{CH}_{3} \mathrm{COO}\right)_{2}+2 \mathrm{H}_{2} \mathrm{O} \longrightarrow \mathrm{CoO}+2 \mathrm{CH}_{3} \mathrm{COOH}+2 \mathrm{H}_{2} \mathrm{O} \\
2 \mathrm{Fe}_{3} \mathrm{O}_{4}+3 \mathrm{CoO} \underset{\text { ultrasound/cavitation }}{\stackrel{[\mathrm{O}]}{\longrightarrow}} 3 \mathrm{CoFe}_{2} \mathrm{O}_{4}
\end{gathered}
$$


Transient cavitation in the reaction mixture leads to in-situ generation of $\mathrm{H}_{2} \mathrm{O}_{2}$ as follows. During expansion of the cavitation bubble, large amount of water vapor evaporates into the bubble and diffuses to the core of the bubble. During the ensuing compression phase, the bubble contracts and the vapor starts diffusing back to the bubble wall (or gas-liquid interface). However, during final moments of the collapse, the bubble wall velocity becomes extremely fast and all of the vapor that has entered the bubble cannot escape (or diffuse back to the bubble wall and condense). This water vapor gets entrapped in the bubble and is subjected to extreme conditions ( $~ 5000 \mathrm{~K}$ temperature and $\sim 500$ bar pressure) generated in the bubble at the moment of transient collapse and undergoes dissociation to generate radicals [22]:

$$
\mathrm{H}_{2} \mathrm{O} \longrightarrow \mathrm{H}^{\bullet}+{ }^{\bullet} \mathrm{OH}
$$

The hydroxyl radicals generated by the bubble can recombine to yield hydrogen peroxide that leads to oxidation of hydroxide to oxides:

$$
\begin{gathered}
{ }^{\circ} \mathrm{OH}+{ }^{\bullet} \mathrm{OH} \longrightarrow \mathrm{H}_{2} \mathrm{O}_{2} \\
\mathrm{H}_{2} \mathrm{O}+\mathrm{O}^{\bullet} \longrightarrow{ }^{\bullet} \mathrm{OH}+{ }^{\bullet} \mathrm{OH} \\
\mathrm{H}_{2} \mathrm{O}+\mathrm{H}^{\bullet} \longrightarrow{ }^{\bullet} \mathrm{OH}+\mathrm{H}_{2} \\
\mathrm{HO}_{2}+\mathrm{H}^{\bullet} \longrightarrow{ }^{\bullet} \mathrm{OH}+{ }^{\bullet} \mathrm{OH}
\end{gathered}
$$

Alternatively, direct thermal decomposition of hydroxide particles can also occur in the thin liquid shell surrounding the cavitation bubble in which the temperature reaches moderately high values $(\sim 400-600 \mathrm{~K})$ at the moment of transient collapse of the cavitation bubbles [20, 23]. In our previous papers [24-32], we have reported extensive simulations of cavitation bubble dynamics using the diffusion limited model of Toegel et al. [33] under variety of conditions that give quantitative confirmation of above physical and chemical effects of cavitation bubble dynamics. We refer the interested readers to these papers for greater details on this subject.

A blackish solid precipitate was obtained as a product after $30 \mathrm{~min}$ of sonication. The precipitate was separated by centrifugation for $20 \mathrm{~min}$ at $6000 \mathrm{rpm}$ (make: Hermile, Model: Z300). The solid product was then dried in a hot air oven for overnight at $100^{\circ} \mathrm{C}$ and characterized using powder X-ray diffraction (make: Bruker, Model: Advanced D8) to ascertain formation of ferrite phase.

In an interesting paper, Dang et al. [38] have reported the sonochemical synthesis of $\mathrm{BaTiO}_{3}$ particles through sol suspension route using $\mathrm{BaCl}_{2}$ and $\mathrm{TiCl}_{4}$ precursors. In a subsequent paper, Yasui and Kato [39] have presented a numerical simulation of oriented aggregation of sonochemically synthesized $\mathrm{BaTiO}_{3}$ nanocrystals. In the study of Dang et al. [38], the Ti-based sol suspension was obtained by first preparing a solution of $\mathrm{BaCl}_{2}$ and later adding $\mathrm{TiCl}_{4}$ to it. Later the $\mathrm{pH}$ of the sol suspension was adjusted to 14 , with temperature being $80^{\circ} \mathrm{C}$. This suspension was sonicated at different power levels to yield $\mathrm{BaTiO}_{3}$ due to reaction induced between colloidal particles by collisions between them driven by transient cavitation events. A similar route such as this may

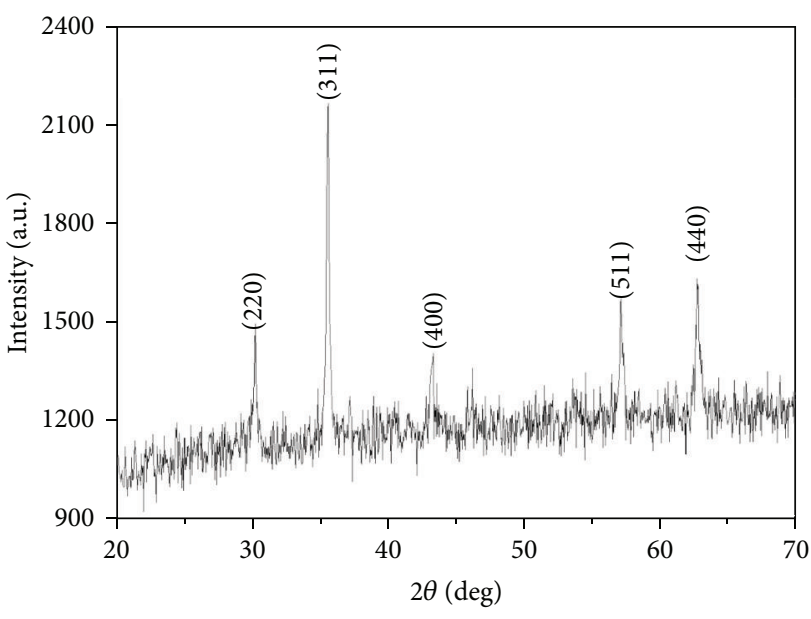

FIGURE 2: X-ray diffraction spectra of $\mathrm{CoFe}_{2} \mathrm{O}_{4}$ (without external calcination) at room temperature.

also occur in the present case leading to ferrite formation. However, we are unable to distinguish between this route and the mechanism that we have proposed above.

2.4. Characterization of the Solid Product. It should be specifically mentioned that external calcination was not applied to the solid product obtained after sonication. Characterization of the dried solid powder resulting from experiments was done using X-ray powder diffractometer (make: Bruker, Model: Advanced D8) with monochromatic $\mathrm{CuK}_{\alpha}(\lambda=$ $1.5406 \AA$ ) radiation operated at $40 \mathrm{kV}$ and $40 \mathrm{~mA}$ in the range from 20 to $70^{\circ}$. The mean crystallite particle size $\left(D_{\mathrm{xrd}}\right)$ of the product was calculated from the most intense peak observed at (311) using Debye-Scherer equation [40, 41]: $D_{\mathrm{xrd}}=0.9 \times \lambda /(\beta \times \cos \theta)$, where $\lambda$ is the $\mathrm{X}$-ray wavelength, $\beta$ is the half width of the relevant diffraction peak, and $\theta$ is the Bragg's angle. The morphology of the cobalt ferrite nano-particles was determined using field emission scanning electron microscope (FE-SEM, Model: SIGMA VP, make: Carl Zeiss Microscopy GmbH, Germany). The magnetic characteristics of the ferrite particles were determined using vibrating sample magnetometer (VSM, make: Lakeshor, Model: 7410).

\section{Results and Discussion}

The results of the experiments have been presented in Figures 2,3 , and 4 . The X-ray diffractogram of the solid product was obtained after sonication. The diffraction peaks corresponding to characteristic crystallographic planes at spinel structure of ferrites [(220), (311), (400), (511), and (440)] are evident in Figure 2 . The ferrite phase is relatively pure in that no presence of other phases like hematite $\left[\left(\alpha-\mathrm{Fe}_{2} \mathrm{O}_{3}\right)\right.$ between (220) and (311) or $\mathrm{Fe}_{3} \mathrm{O}_{4}$ at (333)] or cobalt oxide is seen. The average crystal size of particles, as calculated from DebyeScherer formula, is $24 \mathrm{~nm}$. It is noteworthy that the cobalt ferrite was formed during sonication itself, without external calcination of the material, confirms our earlier hypothesis 


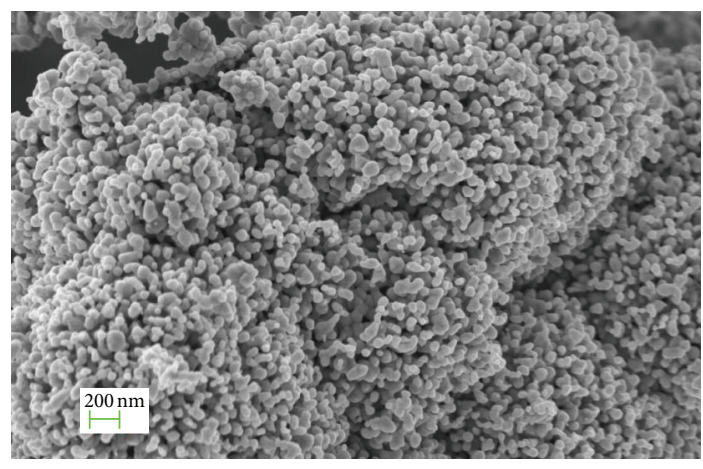

(a)

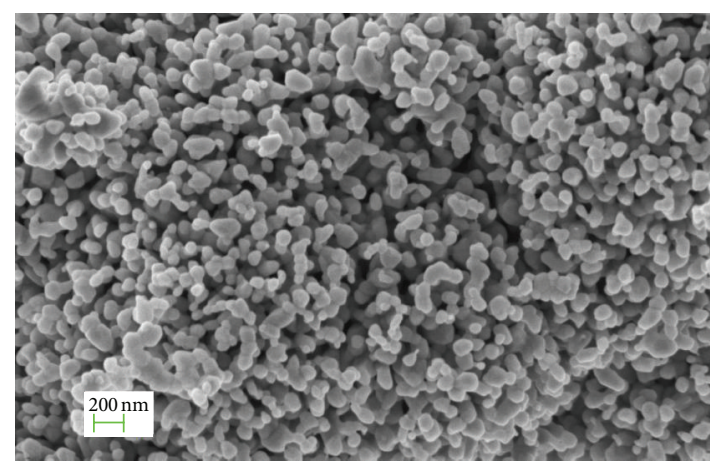

(b)

Figure 3: FE-SEM images of cobalt ferrite. (a) $64 \mathrm{KX}$ and (b) $100 \mathrm{KX}$.

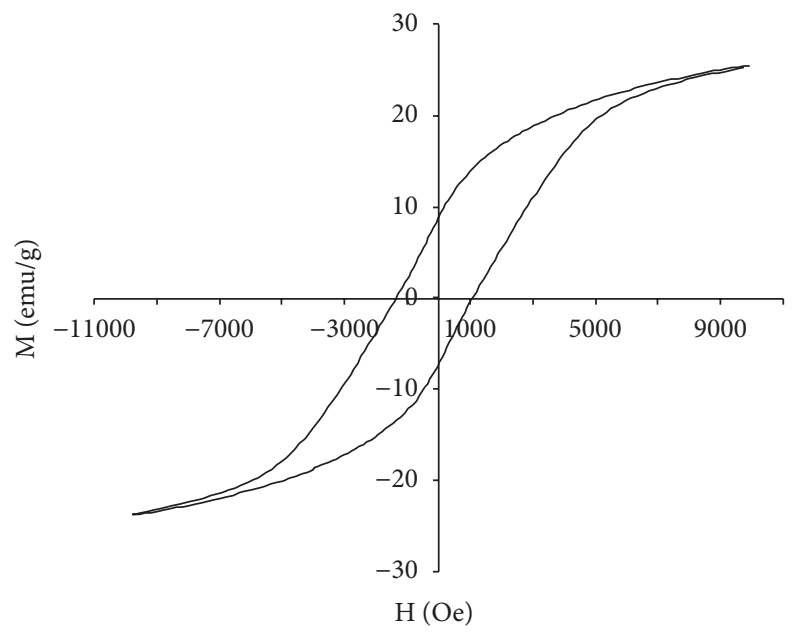

Figure 4: Room temperature M-H curve for $\mathrm{CoFe}_{2} \mathrm{O}_{4}$.

of in-situ micro-calcination of the oxide precursors induced due to the energetic collisions between the particles, as they get drifted in high pressure amplitude shock wave generated by the cavitation bubble. The FE-SEM micrographs of the as-synthesized ferrite particles are shown in Figure 3. These micrographs show agglomerates of nearly spherical particles. Determination of exact particle size from these pictures is thus difficult. Nonetheless the crystalline structure of the particles can be deduced from the uniformity of the particle sizes. The room temperature magnetization curve of the as-synthesized cobalt ferrite particles is given in Figure 4. The saturation magnetization of the sample is $25.7 \mathrm{emu} / \mathrm{g}$, with magnetic remanence of $8.78 \mathrm{emu} / \mathrm{g}$. These values are much smaller than the magnetic saturation reported for bulk $\mathrm{CoFe}_{2} \mathrm{O}_{4}$ material, that is, $72 \mathrm{emu} / \mathrm{g}[19,42]$. Significantly lower values of saturation magnetization observed for our particles confirm its nanocrystalline nature. Shafi et al. [19] have discussed possible causes that lead to this effect. The size of the magnetic particle determines its energy in an external field. This relation is essentially through the number of magnetic molecules in an individual magnetic domain.
With reduction in particle size, the energy of the particle decreases. As the energy becomes comparable to $k T$ ( $k$ : Boltzmann constant, $T$ : Temperature): thermal fluctuations will dominate causing reduction in the total magnetic moment. The reduction in saturation magnetization could be consequence of noncollinear spin arrangement. Cobalt ferrite is essentially an inverse spinel with collinear ferrimagnetic spin structure in the bulk form. However, for particle size in nanorange, there could be non-collinear spin arrangement at or near the surface of the particle that causes reduction in saturation magnetization. Another property which is of relevance to saturation magnetization is the surface-tovolume ratio. The larger this ratio (as for the particles in nanometer range) the magnetic molecules on surface lack proper coordination due to which their spins are disturbed, and total magnetization is reduced. Goodarz Naseri et al. [34] have reported that the relationship between coercivity field and remanence ratio and the saturation magnetization is not simple in that no definite trends are observed. Goodarz Naseri et al. [34] have concluded that the value of remanence ratio $(R)$, which varies between 0 and 1 , is representative of existence or absence of different types of intergrain group exchanges. For $R<0.5$, the particles interact by magnetostatic interaction, while $R=0.5$ indicates randomly oriented noninteracting particles, which undergo coherent rotations. For $0.5<R<1$ indicates existence of exchange coupling particles. According to this criterion, the particles interaction in the as-synthesized cobalt ferrite is through magnetostatic interaction.

Table 1 gives a comparative account of the results of present study with published literature. It could be seen that the particle size as well as magnetization characteristics of the as-synthesized particles is at par with the particles synthesized using conventional techniques.

\section{Conclusion}

In this study, we have explored the sonochemical route of synthesis of cobalt ferrite nano-particles. The precursors are the metal acetates that are hydrolyzed and oxidized under ultrasound irradiation to form metal oxides. In-situ microcalcination of the oxide particles induced due to high 
TABLE 1: Characterization of cobalt ferrite nanoparticles and comparison with the literature.

\begin{tabular}{|c|c|c|c|c|c|}
\hline Method of synthesis & Particle size $(\mathrm{nm})$ & Coercivity (Oe) & $\begin{array}{c}\text { Magnetic saturation } \\
M_{s}(\mathrm{emu} / \mathrm{g})\end{array}$ & $\begin{array}{c}\text { Magnetic remanence } \\
M_{r}(\mathrm{emu} / \mathrm{g})\end{array}$ & $\begin{array}{l}\text { Remanence ratio } \\
\left(R=M_{r} / M_{s}\right)\end{array}$ \\
\hline Present study & 24 & 1049 & $\begin{array}{c}25.7 \\
\text { (No calcination) }\end{array}$ & 8.78 & 0.341 \\
\hline Autocombustion [10] & 22.7 & 760 & $\begin{array}{c}24.46 \\
\left(T_{\text {calc }}=200^{\circ} \mathrm{C}\right)\end{array}$ & 8.80 & 0.359 \\
\hline $\begin{array}{l}\text { Sonochemical synthesis } \\
\text { through carbonyl route [19] }\end{array}$ & $<10$ & ND & $\begin{array}{c}\text { Superparamagnetic } \\
\text { behavior without } \\
\text { calcination } \\
22 \\
\left(T_{\text {calc }}=450^{\circ} \mathrm{C}\right) \\
45 \\
\left(T_{\text {calc }}=700^{\circ} \mathrm{C}\right)\end{array}$ & ND & ND \\
\hline Thermal treatment [34] & 41 & 1002 & $\begin{array}{c}28.5 \\
\left(T_{\text {calc }}=650^{\circ} \mathrm{C}\right)\end{array}$ & 11.61 & 0.407 \\
\hline Sol-gel [5] & 15 & 1215 & $\begin{array}{c}67.0 \\
\left(T_{\text {calc }}=570^{\circ} \mathrm{C}\right)\end{array}$ & 30.2 & 0.45 \\
\hline Coprecipitation [35] & 13.8 & 193 & $\begin{array}{c}58.3 \\
\left(T_{\text {calc }}=80^{\circ} \mathrm{C}\right)\end{array}$ & 16.5 & 0.28 \\
\hline Microemulsion [36] & $<50$ & 1440 & $\begin{array}{c}65.0 \\
\left(T_{\text {calc }}=600^{\circ} \mathrm{C}\right)\end{array}$ & 29 & 0.44 \\
\hline Mechanical Milling [37] & 12.2 & 940 & $\begin{array}{c}81.2 \\
\left(T_{\text {calc }}=22^{\circ} \mathrm{C}\right)\end{array}$ & 50.61 & 0.62 \\
\hline
\end{tabular}

$T_{\text {calc }}$ : calcination temperature, ND: not determined.

energy collisions between the particles due to the shock waves generated by cavitation bubble causes synthesis of ferrite. Most notably, no external calcination is needed. Characterization of as-synthesized particles with XRD, FE-SEM, and VSM reveals that ferrite particles have inverse spinel crystalline structure. The physical and magnetic properties of the as-synthesized particles are comparable with those synthesized using conventional techniques.

\section{Conflict of Interests}

The authors of this paper declare no conflict of interests of any kind.

\section{Acknowledgments}

Authors gratefully acknowledge stimulating discussions with Proffessor M. Sivakumar (University of Nottingham, Malaysia) during the preliminary stage of project on sonochemical ferrite synthesis. The authors also acknowledge the Central Instruments Facility (CIF) of I.I.T. Guwahati for providing SEM and VSM facility for analysis of ferrite samples.

\section{References}

[1] M. G. Naseri and E. B. Saion, "Crystalization in spinel ferrite nanoparticles," in Advances in Crystallization Processes, pp. 349380, 2012.

[2] E. C. Snelling, Soft Ferrites: Properties and Applications, Butterworth, London, UK, 2nd edition, 1989.
[3] K. Maaz, A. Mumtaz, S. K. Hasanain, and A. Ceylan, "Synthesis and magnetic properties of cobalt ferrite $\left(\mathrm{CoFe}_{2} \mathrm{O}_{4}\right)$ nanoparticles prepared by wet chemical route," Journal of Magnetism and Magnetic Materials, vol. 308, no. 2, pp. 289-295, 2007.

[4] J.-S. Jung, J.-H. Lim, K.-H. Choi et al., " $\mathrm{CoFe}_{2} \mathrm{O}_{4}$ nanostructures with high coercivity," Journal of Applied Physics, vol. 97, no. 10, Article ID 10F306, pp. 1-3, 2005.

[5] B. G. Toksha, S. E. Shirsath, S. M. Patange, and K. M. Jadhav, "Structural investigations and magnetic properties of cobalt ferrite nanoparticles prepared by sol-gel auto combustion method," Solid State Communications, vol. 147, no. 11-12, pp. 479-483, 2008.

[6] K. Winiarska, I. Szczygieł, and R. Klimkiewicz, "Manganese-zinc ferrite synthesis by the sol-gel autocombustion method. Effect of the precursor on the ferrite's catalytic properties," Industrial and Engineering Chemistry Research, vol. 52, pp. 353361, 2013.

[7] Y. Ahn, E. J. Choi, S. Kim, and H. N. Ok, "Magnetization and Mössbauer study of cobalt ferrite particles from nanophase cobalt iron carbonate," Materials Letters, vol. 50, no. 1, pp. 47-52, 2001.

[8] D. O. Yener and H. Giesche, "Synthesis of pure and manganese-, nickel-, and zinc-doped ferrite particles in water-in-oil microemulsions," Journal of the American Ceramic Society, vol. 84, no. 9, pp. 1987-1995, 2001.

[9] Y. Lee, J. Lee, C. J. Bae et al., "Large-scale synthesis of uniform and crystalline magnetite nanoparticles using reverse micelles as nanoreactors under reflux conditions," Advanced Functional Materials, vol. 15, pp. 503-509, 2005.

[10] S. H. Xiao, W. F. Jiang, L. Y. Li, and X. J. Li, "Low-temperature auto-combustion synthesis and magnetic properties of cobalt ferrite nanopowder," Materials Chemistry and Physics, vol. 106, no. 1, pp. 82-87, 2007. 
[11] I. Elahi, R. Zahira, K. Mehmood, A. Jamil, and N. Amin, "Coprecipitation synthesis, physical and magnetic properties of manganese ferrite powder," African Journal of Pure and Applied Chemistry, vol. 6, pp. 1-5, 2012.

[12] M. Sivakumar, A. Gedanken, W. Zhong et al., "Nanophase formation of strontium hexaferrite fine powder by the sonochemical method using $\mathrm{Fe}(\mathrm{CO})_{5}$," Journal of Magnetism and Magnetic Materials, vol. 268, no. 1-2, pp. 95-104, 2004.

[13] M. Sivakumar, A. Gedanken, D. Bhattacharya et al., "Sonochemical synthesis of nanocrystalline rare earth orthoferrites using $\mathrm{Fe}(\mathrm{CO})_{5}$ precursor," Chemistry of Materials, vol. 16, no. 19, pp. 3623-3632, 2004.

[14] M. Sivakumar, A. Gedanken, W. Zhong et al., "Sonochemical synthesis of nanocrystalline $\mathrm{LaFeO}_{3}$," Journal of Materials Chemistry, vol. 14, no. 4, pp. 764-769, 2004.

[15] B. R. Reddy, T. Sivasankar, M. Sivakumar, and V. S. Moholkar, "Physical facets of ultrasonic cavitational synthesis of zinc ferrite particles," Ultrasonics Sonochemistry, vol. 17, no. 2, pp. 416-426, 2010.

[16] H. A. Choudhury, A. Choudhary, M. Sivakumar, and V. S. Moholkar, "Mechanistic investigation of the sonochemical synthesis of zinc ferrite," Ultrasonics Sonochemistry, vol. 20, pp. 294-302, 2013.

[17] K. S. Suslick, Ultrasound: Its Chemical, Physical and Biological Effects, VCH, New York, NY, USA, 1998.

[18] S. J. Doktycz and K. S. Suslick, "Interparticle collisions driven by ultrasound," Science, vol. 247, no. 4946, pp. 1067-1069, 1990.

[19] K. V. P. M. Shafi, A. Gedanken, R. Prozorov, and J. Balogh, "Sonochemical preparation and size-dependent properties of nanostructured $\mathrm{CoFe}_{2} \mathrm{O}_{4}$ particles," Chemistry of Materials, vol. 10, no. 11, pp. 3445-3450, 1998.

[20] A. Kotronarou, G. Mills, and M. R. Hoffmann, "Ultrasonic irradiation of p-nitrophenol in aqueous solution," Journal of Physical Chemistry, vol. 95, no. 9, pp. 3630-3638, 1991.

[21] T. Sivasankar, A. W. Paunikar, and V. S. Moholkar, "Mechanistic approach to enhancement of the yield of a sonochemical reaction," AIChE Journal, vol. 53, no. 5, pp. 1132-1143, 2007.

[22] K. S. Suslick, "Sonochemistry," Science, vol. 247, no. 4949, pp. 1439-1445, 1990.

[23] I. Hua, R. H. Höchemer, and M. R. Hoffmann, "Sonpchemical degradation of p-nitrophenol in a parallel-plate near-field acoustical processor," Environmental Science and Technology, vol. 29, no. 11, pp. 2790-2796, 1995.

[24] J. S. Krishnan, P. Dwivedi, and V. S. Moholkar, "Numerical investigation into the chemistry induced by hydrodynamic cavitation," Industrial and Engineering Chemistry Research, vol. 45, no. 4, pp. 1493-1504, 2006.

[25] S. Chakma and V. S. Moholkar, "Numerical simulation and investigation of system parameters of sonochemical process," Chinese Journal of Engineering, vol. 2013, Article ID 362682, 14 pages, 2013.

[26] T. Sivasankar and V. S. Moholkar, "Mechanistic features of the sonochemical degradation of organic pollutants," AIChE Journal, vol. 54, no. 8, pp. 2206-2219, 2008.

[27] T. Sivasankar and V. S. Moholkar, "Physical features of sonochemical degradation of nitroaromatic pollutants," Chemosphere, vol. 72, no. 11, pp. 1795-1806, 2008.

[28] T. Sivasankar and V. S. Moholkar, "Mechanistic approach to intensification of sonochemical degradation of phenol," Chemical Engineering Journal, vol. 149, no. 1-3, pp. 57-69, 2009.
[29] T. Sivasankar and V. S. Moholkar, "Physical insight into the sonochemical degradation of 2,4-dichlorophenol," Environmental Technology, vol. 31, no. 14, pp. 1483-1494, 2010.

[30] T. Sivasankar and V. S. Moholkar, "Physical insights into the sonochemical degradation of recalcitrant organic pollutants with cavitation bubble dynamics," Ultrasonics Sonochemistry, vol. 16, no. 6, pp. 769-781, 2009.

[31] S. Chakma and V. S. Moholkar, "Physical mechanism of sonofenton process," AIChE Journal, vol. 59, no. 11, pp. 4303-4313, 2013.

[32] N. K. Morya, P. K. Iyer, and V. S. Moholkar, "A physical insight into sonochemical emulsion polymerization with cavitation bubble dynamics," Polymer, vol. 49, no. 7, pp. 1910-1925, 2008.

[33] R. Toegel, B. Gompf, R. Pecha, and D. Lohse, "Does water vapor prevent upscaling sonoluminescence?” Physical Review Letters, vol. 85, no. 15, pp. 3165-3168, 2000.

[34] M. Goodarz Naseri, E. B. Saion, H. Abbastabar Ahangar, A. H. Shaari, and M. Hashim, "Simple synthesis and characterization of cobalt ferrite nanoparticles by a thermal treatment method," Journal of Nanomaterials, vol. 2010, Article ID 907686, 8 pages, 2010.

[35] Y. I. Kim, D. Kim, and C. S. Lee, "Synthesis and characterization of $\mathrm{CoFe}_{2} \mathrm{O}_{4}$ magnetic nanoparticles prepared by temperaturecontrolled coprecipitation method," Physica B, vol. 337, no. 1-4, pp. 42-51, 2003.

[36] V. Pillai and D. O. Shah, "Synthesis of high-coercivity cobalt ferrite particles using water-in-oil microemulsions," Journal of Magnetism and Magnetic Materials, vol. 163, no. 1-2, pp. 243248, 1996.

[37] E. Manova, B. Kunev, D. Paneva et al., "Mechano-synthesis, characterization, and magnetic properties of nanoparticles of cobalt ferrite, $\mathrm{CoFe}_{2} \mathrm{O}_{4}$," Chemistry of Materials, vol. 16, no. 26, pp. 5689-5696, 2004.

[38] F. Dang, K. Kato, H. Imai, S. Wada, H. Haneda, and M. Kuwabara, "Characteristics of $\mathrm{BaTiO}_{3}$ particles sonochemically synthesized in aqueous solution," Japanese Journal of Applied Physics, vol. 48, no. 9, Article ID 09KC02, 2009.

[39] K. Yasui and K. Kato, "Numerical simulations of oriented aggregation of sonochemically synthesized $\mathrm{BaTiO}_{3}$ nanocrystals," Proceedings of Meetings on Acoustics, vol. 15, Article ID 045002, pp. 1-7, 2012, 163rd Meeting Acoustical Society of America, Hong Kong.

[40] V. Musat, O. Potecasu, R. Belea, and P. Alexandru, "Magnetic materials from co-precipitated ferrite nanoparticles," Materials Science and Engineering B, vol. 167, no. 2, pp. 85-90, 2010.

[41] Y. Köseoğlu, F. Alan, M. Tan, R. Yilgin, and M. Öztürk, "Low temperature hydrothermal synthesis and characterization of Mn doped cobalt ferrite nanoparticles," Ceramics International, vol. 38, no. 5, pp. 3625-3634, 2012.

[42] K. Haneda and A. H. Morrish, "Noncollinear magnetic structure of $\mathrm{CoFe}_{2} \mathrm{O}_{4}$ small particles," Journal of Applied Physics, vol. 63 , no. 8 , pp. 4258-4260, 1988. 

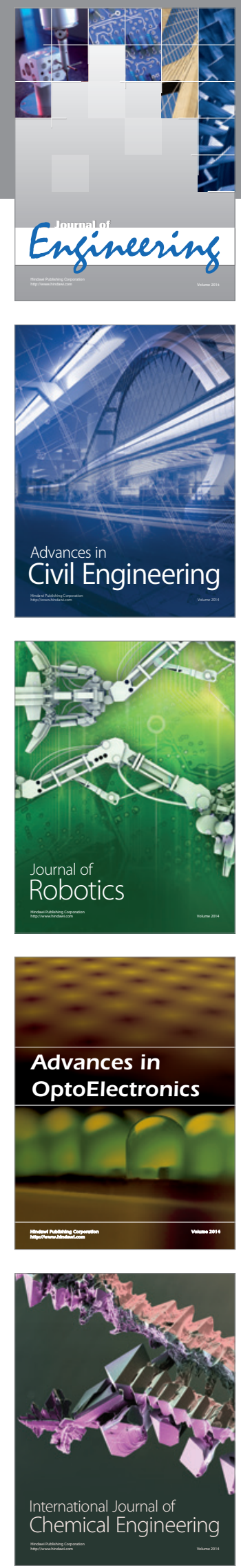

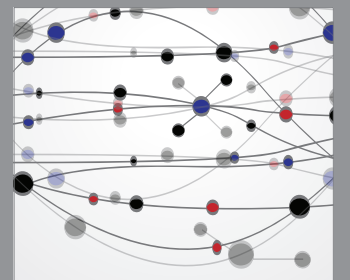

The Scientific World Journal
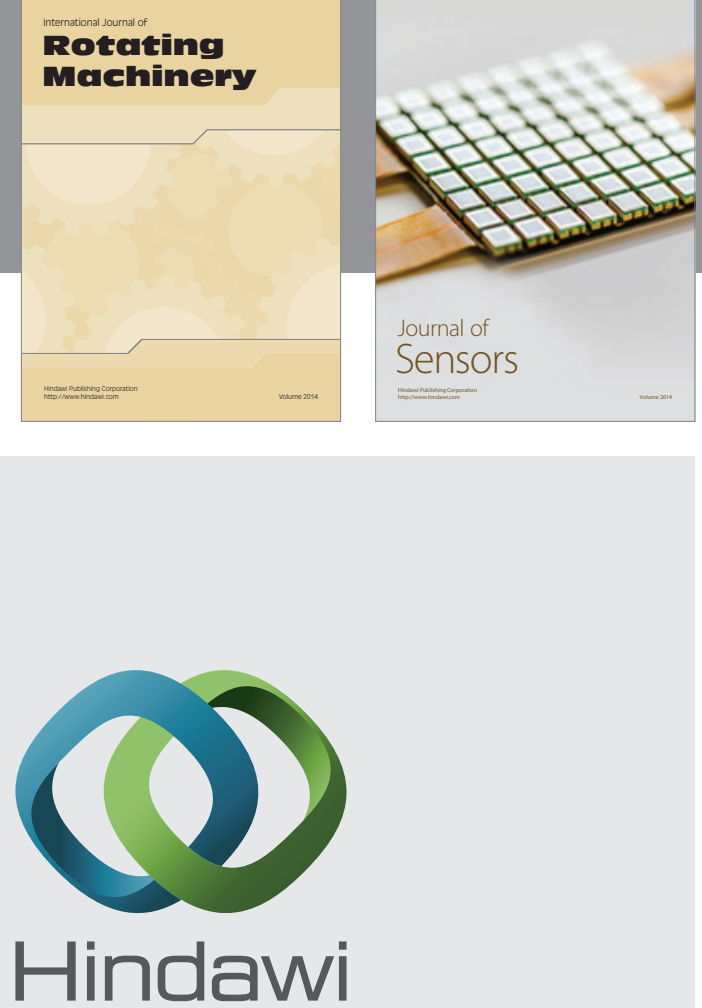

Submit your manuscripts at http://www.hindawi.com
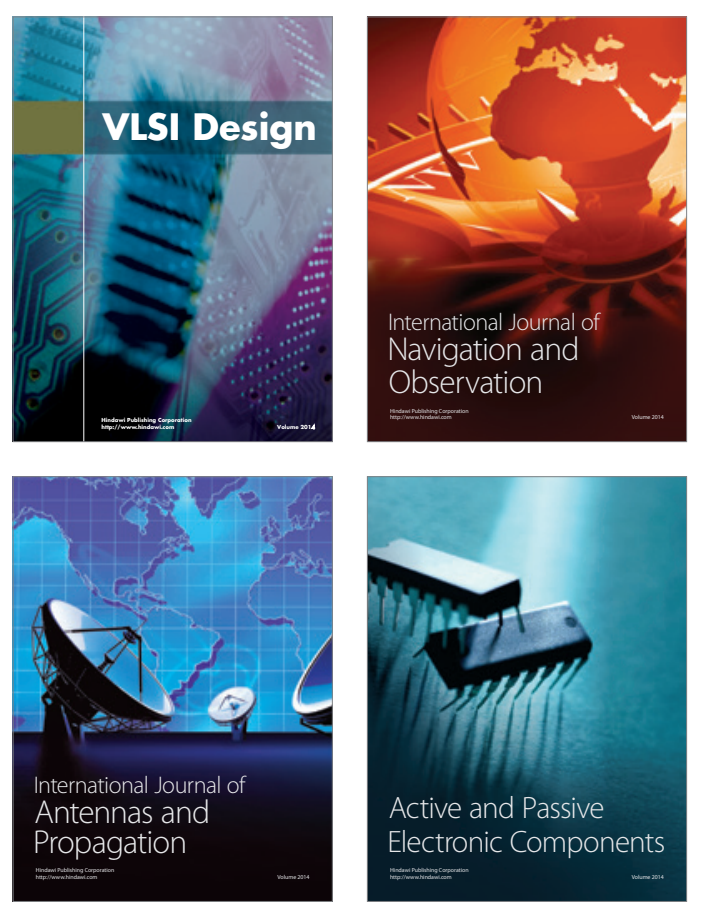
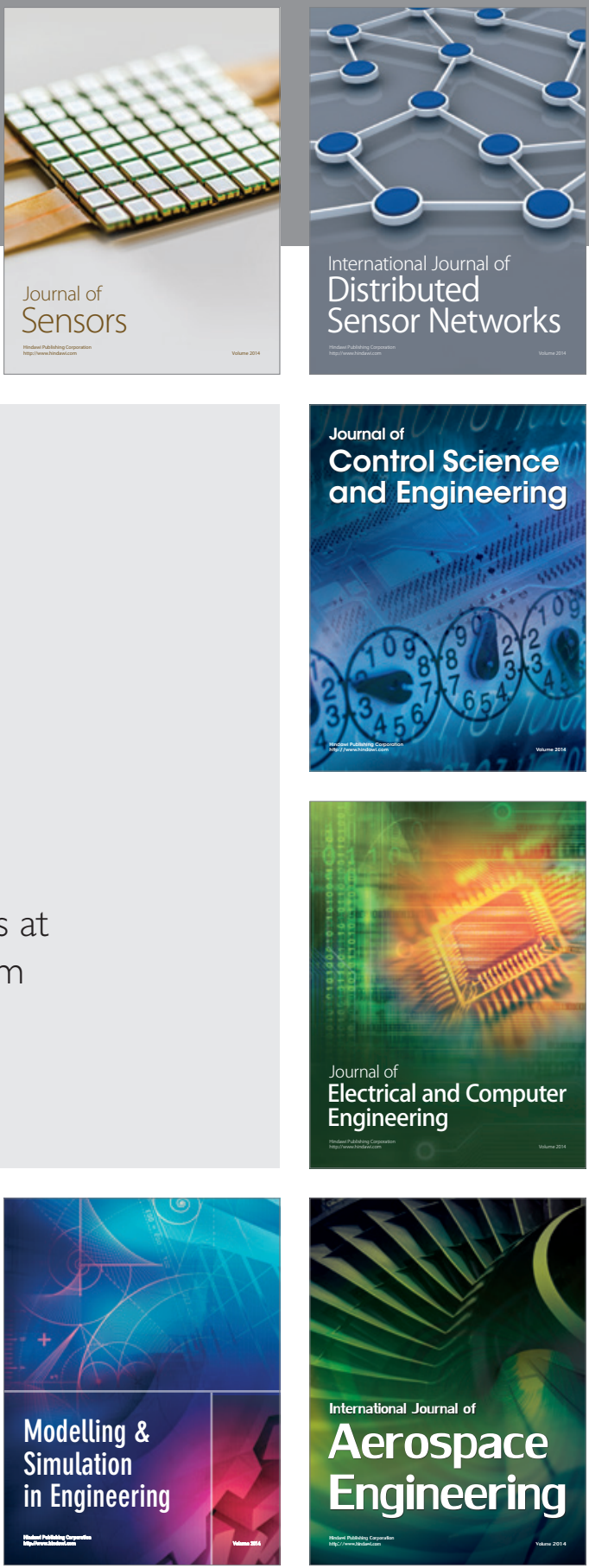

Journal of

Control Science

and Engineering
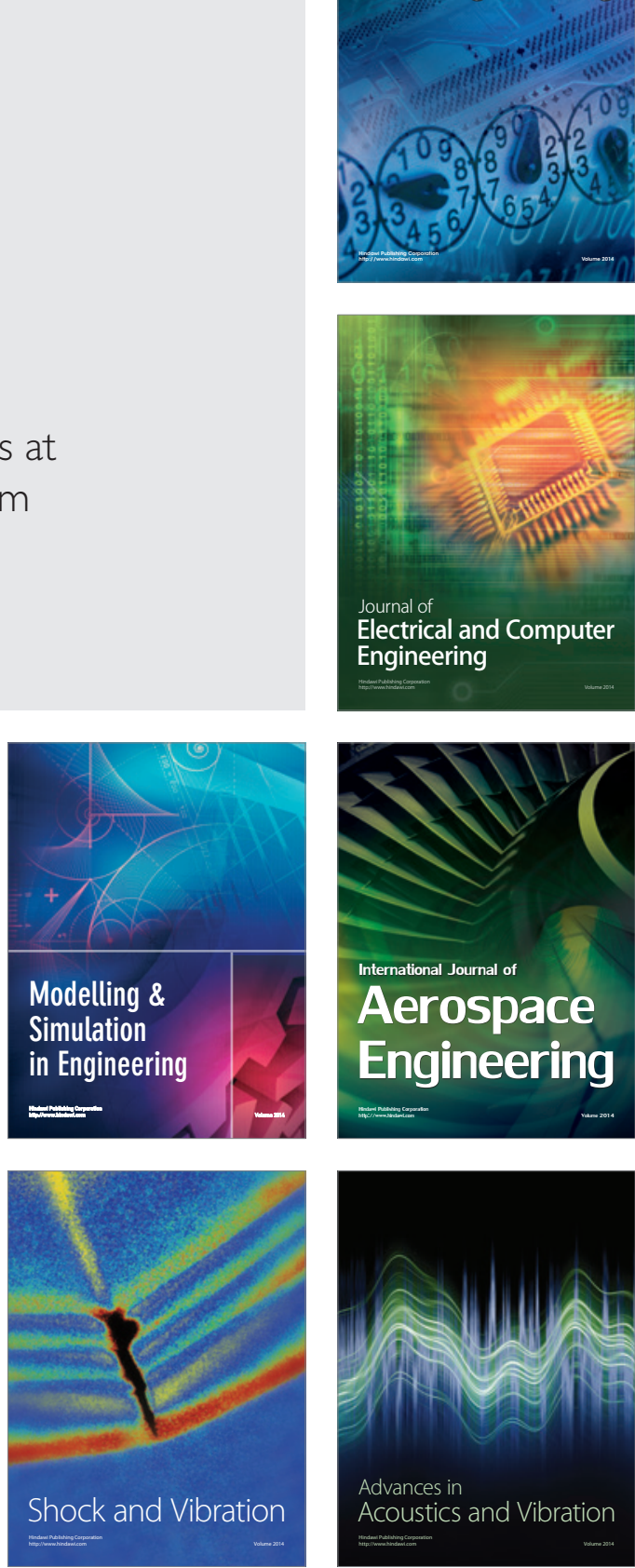